\title{
MARX E A CONTRADITORIEDADE DA RELAÇÃO SOCIAL DE PRODUÇÃO ESPECIFICAMENTE CAPITALISTA
}

Elcemir Paço Cunha ${ }^{1}$

\section{Resumo}

O artigo é um ensaio que explora a contraditoriedade da relação social de produção especificamente capitalista a partir dos delineamentos fornecidos pelo próprio Marx, especialmente nos chamados Grundrisse e em $O$ Capital. A crítica de Marx à produção capitalista e ao microcosmo de sua reprodução, isto é, a empresa capitalista, parece ter sido considerada apenas unilateralmente por grande parte dos estudiosos marxistas. A inspeção do estatuto de tal relação de produção no interior dos reflexionamentos propriamente marxianos denota que Marx mesmo reconhecia a "contraditoriedade" inerente a tal relação. Em outros termos, o significado efetivo do revolucionamento provocado pelo desenvolvimento da relação social de produção sob a forma da manufatura, da oficina maquinal, da fábrica, da grande indústria, da empresa capitalista moderna é aprendido apenas parcialmente se considerada tão somente como relação de geração de mais-valor ou ainda como instância de controle. Por contraditoriedade é preciso entender que Marx não faz uma análise unilateral da produção capitalista nem dos seus microcosmos. Não reconhece nela apenas a forma da produção do maisvalor, a realização da subsunção formal e real do trabalho ao capital, mas também outros elementos que fazem de tal produção a forma mais desenvolvida até então existente, a forma na qual as forças produtivas e a individualidade humana alcançaram o mais alto desenvolvimento, embora não seja de forma alguma o último e instransponível modo de produção nem que seja isento de estranhamentos profundos.

Palavras-chave: Contraditoriedade. Relação Social de Produção Capitalista. Marx.

\section{MARX AND THE CONTRADICTORITY OF THE CAPITALIST SOCIAL RELATION OF PRODUCTION}

\footnotetext{
${ }^{1}$ Doutor em Administração pela Universidade Federal de Minas Gerais. Professor adjunto da Universidade Federal de Juiz de Fora. E-mail: paco.cunha@facc.ufjf.br Revista Brasileira de Estudos Organizacionais · v. 3. n. 1, p. 42-62, jun.2016, eISSN: 2447-4851 Doi 10.21583/2447-4851.rbeo.2016.v3n1.62 Sociedade Brasileira de Estudos Organizacionais
} 


\begin{abstract}
The essay explores the contradictority of the capitalist social relation of production through Marx's outlines in Grundrisse and The Capital. The Marx's critic to capitalist production and to the microcosm of its reproduction (i.e. the enterprise), seems to be considered unilaterally by the great part of Marxists scholars. The inspection of the character of such relation of production into the Marxian reflections shows that Marx acknowledged its immanent contradictory. In another word, the concrete meaning of the revolutionising caused by the development of the social relation of production under the form of manufacture, of mechanic atelier, of fabric, of great industry, of modern enterprise, is apprehended partially if it is considered only as a relation to the generation of plus-value or a place of control. One must understand by contradictority that Marx did not analyse unilaterally the capitalist production or its microcosm. He does not recognise only its character as a production of plus-value, the materialization of the formal and real subsuntion of labour to capital, but also elements which make such production the most hitherto existing developed form in which the productivity forces and the human individuality have achieved the highest development under an alienated form, albeit it is by no means insuperable, and the last mode of production.
\end{abstract}

Keywords: Contradictority. Capitalist Social Relation of Production. Marx.

\title{
TÍTULO EM ESPANHOL
}

\section{Resumen}

El ensayo discute la contradictoridad de las relaciones sociales de producción específicamente capitalista a partir de los delineamientos propiciados por Marx, especialmente en los llamados Grundrisse y en El Capital. La crítica de Marx a la producción capitalista y al microcosmo de su reproducción, o sea, la empresa capitalista, parece ter sido considerada unilateralmente por grande parte de los estudiosos marxistas. La inspección del estatuto de tal relación de producción en el interior de reflexiones propiamente marxianas denota que Marx reconocía la "contradictoridad" inherente a tal relación. En otras palabras, el significado efectivo del revolucionamento provocado por el desarrollo de la relación social de producción bajo su forma de manufactura, de oficinal maquinal, de fábrica, de grande industria, de empresa capitalista moderna, es aprendida apenas parcialmente se considerada tan solamente 
como una relación de generación de plus-valía o aún como instancia de control. Por contradictoridad es necesario entender que Marx no hacía un análisis unilateral de la producción capitalista o de sus microcosmos. No reconoce en ella solamente una forma de producción de plus-valía, pero también otros elementos que hacen de tal producción la forma más desarrollado hasta entonces existente, la forma en la cual las fuerzas productivas y la individualidad humana alcanzaran el más elevado desarrollo, aún que no sea de manera alguna el último e eterno modo de producción ni que no tenga profundos extrañamientos.

Palabras-clave: Contradictoridad. Relación social de producción capitalista. Marx.

\section{Introdução}

É amplamente divulgada, mas não necessariamente compreendida, a crítica que Marx estabeleceu em relação à produção capitalista e ao capital propriamente, às condições objetivas de sua constituição e reprodução. Insere-se nessa crítica a empresa capitalista, o microcosmo da reprodução sociometabólica do capital, como prefere Mészáros (2002), tomada aqui a partir dos próprios lineamentos marxianos como relação social de produção especificamente capitalista, isto é, tal microcosmo é ele mesmo uma relação social de produção sob a forma particular da sociabilidade capitalista. Mas a inspeção do estatuto de tal relação de produção no interior dos seus lineamentos denota que Marx mesmo reconhecia a "contraditoriedade" inerente a tal relação, derrubando grande parte das considerações unilaterais amplamente divulgadas nos séculos XX e XXI. Em outros termos, o significado efetivo do revolucionamento provocado pelo desenvolvimento da relação social de produção sob a forma da manufatura, da oficina maquinal, da fábrica, da grande indústria, da empresa capitalista moderna é aprendido apenas parcialmente.

Neste ensaio cabe esboçar algumas considerações acerca da "contraditoriedade" que Marx constata nas relações sociais estabelecidas e por meio das quais a produção capitalista é levada à diante, incluindo aí o seu próprio limite. Por contraditoriedade é preciso entender que Marx não faz uma análise unilateral da produção capitalista nem dos seus microcosmos correspondentes, pontos finitos de sua reprodução. Não reconhece nela apenas a forma da produção do mais-valor, a realização da subsunção formal e real do trabalho ao capital, mas também outros elementos que fazem de tal produção a forma mais desenvolvida até então existente, a forma na qual as forças produtivas e a individualidade humana alcançaram o mais alto desenvolvimento, embora não seja de 
forma alguma o último e instransponível modo de produção e que também não é isento de profundos estranhamentos. Isso ajuda a demarcar, por fim, a particularidade da relação social de produção capitalista, isto é, o centro de trabalho, aquele microcosmo, como uma relação de exploração mais refinada e civilizada do trabalho e que põe, ela mesma, as condições de sua própria superação e da superação do modo de produção que a comporta.

Não é possível, porém, encontrar um só tópico dedicado a este ponto nos materiais deixados por Marx. Como vários outros elementos tratados no interior dos lineamentos propriamente marxianos, tal contraditoriedade está presente em diferentes aspectos em que se analisa a produção capitalista, isto é, trata-se de um ponto dentro dos pontos, algo que aparece mais incisivamente nos Grundrisse, embora em $O$ Capital elementos também sejam indicados, mostrando que não fora um momento de dúvida da investigação ou de mero momento a ser superado em seguida, páginas adiante, mas sem dúvida uma constatação à maneira do próprio Marx da forma contraditória pela qual o modo de produção capitalista, ou melhor, a sociabilidade humana se apresenta neste estágio do desenvolvimento das forças produtivas.

Seja como for, trata-se de um ponto que remete, primeiramente, à Miséria da filosofia (1950). Na polêmica com Proudhon - que fora muito útil à constatação aqui angular de que a fábrica, assim como a grande indústria, mas também a corporação medieval ou mesmo a empresa capitalista moderna, não são outra coisa senão uma dada forma particular da relação social de produção -, aparece também um aspecto acerca do sentido da "oficina mecânica" na história da humanidade, além da aplicação direta da máquina e do encapsulamento do processo de trabalho pelo processo de valorização. Na polêmica com Proudhon, Marx toma a divisão do trabalho nesta oficina para indicar que estes centros de trabalho significaram a superação dos trabalhos fragmentados. Na passagem, diz Marx (1950, p. 173-4):

O que caracteriza divisão do trabalho na oficina mecânica é que o trabalho perde todo caráter de especialização. Mas, no momento em que todo o desenvolvimento especial cessa, a necessidade de universalidade, a tendência para um desenvolvimento integral do indivíduo começa a se fazer sentir. A oficina mecânica suprime as profissões isoladas e o idiotismo do ofício.

O Sr. Proudhon, pelo fato de não ter compreendido nem sequer esse único aspecto revolucionário da oficina mecânica, dá um passo atrás e propõe ao operário que não faça somente a duodécima parte de um alfinete, mas sucessivamente as doze partes. O operário alcançaria assim a ciência e a consciência de um alfinete. Aí está o trabalho sintético do Sr. Proudhon. Ninguém negará que 
dar um passo adiante e outro atrás é, igualmente, fazer um movimento sintético.

Aqui aparece algo de suma importância à medida que Marx reconhece que, no caso, a oficina mecânica supera o idiotismo do ofício isolado e propicia o aparecimento da necessidade de universalidade. É algo que aparece em vários momentos nos quais Marx mostra o desenvolvimento da relação social de produção capitalista na luta pela superação das relações que marcaram a feudalidade e sua fase superior, centrada no camponês livre disperso em pequenas propriedades. $\mathrm{O}$ desenvolvimento da relação de produção especificamente capitalista pressupôs, assim, a gradativa eliminação da fragmentação dos produtores. É algo que Marx considera precário, rudimentar, isto é, o trabalho no qual o produtor produz isoladamente. Embora neste caso conheça todas as etapas necessárias de uma produção, a própria produção aparece pouco desenvolvida e a própria atividade, idiotizada. E não é para a ciência e consciência de um alfinete que Marx aponta. Revela-se aqui já de início que a suposta "desalienação" pela compreensão do processo produtivo em sua integralidade não passa de engodo se atribuída ao próprio Marx, já que a desalienação para o Mouro não reflete necessariamente o trabalho artesanal, isolado, isto é, não tem nele ângulo de avaliação.

Trata-se de uma posição interessante de ser constata na medida em que é evidenciada também em $O$ Capital ao tratar da cooperação capitalista. Na passagem, Marx mostra os efeitos das jornadas de trabalho combinadas, isto é, como efeito da cooperação, efeitos em seu sentido material, mas também no sentido que tem para o desenvolvimento da individualidade humana. Na passagem, diz Marx (1985a, p. 262; 1962a, p. 348-9)

Em comparação com uma soma igual de jornadas de trabalho isoladas individuais a jornada de trabalho combinada produz maiores quantidades de valor de uso, diminuindo por isso o tempo de trabalho necessário para produzir determinado efeito útil. Se, conforme o caso, ela obtém essa força produtiva mais elevada por aumentar a potência das forças mecânicas do trabalho, ou por estender sua escala espacial de ação, ou por estreitar o campo espacial de produção em relação à escala da produção, ou por mobilizar no momento crítico muito trabalho em pouco tempo, ou por provocar a emulação entre os indivíduos e excitar seus espíritos vitais, ou por imprimir às operações semelhantes de muitos o cunho da continuidade e da multiplicidade, ou por executar diversas operações ao mesmo tempo, ou por economizar os meios de produção mediante seu uso coletivo, ou por emprestar ao trabalho individual o caráter de trabalho social médio, em todas as circunstâncias a força produtiva 
específica da jornada de trabalho combinada é força produtiva social do trabalho ou força produtiva do trabalho social. Ela decorre da própria cooperação. Ao cooperar com outros de um modo planejado, o trabalhador se desfaz de suas limitações individuais e desenvolve a capacidade de seu gênero [Gattungsvermögen].

Nessa passagem sem igual, fica evidente que Marx mostra que sob a cooperação, em que está superada a fragmentação dos produtores, as próprias limitações individuais são superadas e a capacidade do gênero humano é desenvolvida. E como tal cooperação, que aparece nesse lineamento em sua forma abstrata, geral, possui caráter efetivo e está na base mesma da cooperação capitalista, seus efeitos, que ao capital não custam nada, são os mesmos que o da cooperação simples, talvez efeitos ainda mais ampliados dado o desenrolar dos processos técnicos e científicos que acompanham a combinação do trabalho na cooperação capitalista. Não obstante, é preciso reter que se, por um lado, a produção capitalista desenvolve tal cooperação não para outra finalidade senão a autovalorização do capital; por outro lado, é nessa forma de cooperação que o idiotismo do ofício, a fragmentação dos produtores e as limitações individuais se apresentam superados. Nesse sentido, qualquer argumento que sugira que para Marx o ângulo de avaliação negativa do trabalho produtivo é o trabalho artesanal (e.g. GIANNOTTI, 1985), somente pode ser feito se forem esquecidas essas considerações nas quais é, ao contrário, o trabalho produtivo que aparece como mais desenvolvido do que sua forma anterior, embora seja o produtivo aquele trabalho sobre o qual a produção capitalista se assente, isto é, trabalho que valoriza capital forma do trabalho que igualmente deve ser superado numa configuração superior do desenvolvimento das forças produtivas.

Vale ainda reforçar este ponto uma vez que ele é motivo de grande desconforto especialmente para alguns britânicos. Parker (2002) é um dos melhores exemplos, pois no afã de mostrar seu precioso novo conceito na feira dos conceitos abstratos da contemporaneidade, o qual combina cooperação, unidade e organização - chamado orgunity - menciona uma passagem de Marx sobre a diferença entre a cooperação capitalista e a cooperação das formas sociais anteriores para substanciar seu próprio conceito, mas nublando que se trata de tal diferenciação. Na passagem de Parker, aparece assim a cooperação:

Como Marx sugeriu 'cooperação no processo de trabalho [...] é baseada por um lado na propriedade comum dos meios de produção, e por outro no fato de que naqueles casos o individual tem pouco desligamento do cordão umbilical de sua comunidade como a abelha da colmeia' (PARKER, 2002, p. 83). 
É possível recolocar aqui a passagem integral de Marx para uma rápida comparação, desconsiderando a diferença entre as traduções:

A cooperação no processo de trabalho, como a encontramos nas origens culturais da humanidade, predominantemente nos povos caçadores ou eventualmente na agricultura da comunidade indiana, fundamenta-se, por um lado, na propriedade comum das condições de produção e, por outro, na circunstância de que o indivíduo isolado se desligou tão pouco do cordão umbilical da tribo ou da comunidade como a abelha individual da colmeia. Ambos a diferenciam da cooperação capitalista. A esporádica utilização da cooperação em grande escala no mundo antigo, na Idade Média e nas colônias modernas baseia-se em relações diretas de domínio e servidão, na maioria das vezes na escravidão. A forma capitalista pressupõe, ao contrário, desde o princípio o trabalhador assalariado livre, que vende sua força de trabalho ao capital. Historicamente, no entanto, ela se desenvolve em oposição à economia camponesa e ao exercício independente dos ofícios, possuindo esta forma corporativa ou não. Desse confronto, aparece a cooperação capitalista não como uma forma histórica peculiar da cooperação, mas a cooperação mesma como uma forma histórica particular do processo de produção capitalista e que o distingue especificamente (MARX, 1985a, p. 265; MARX, 1962a, p. 354).

Parker (2002) parece indicar que Marx sugere a cooperação que se encontra nas origens culturais da humanidade como uma forma mais adequada da cooperação, sobre a qual, inclusive, ele funda seu orgunity. É possível observar que a parte que o senhor Parker simplesmente suprimiu, isto é, aquela que indica que a cooperação tratada naquele momento é a que aparece entre os povos muito antigos, coloca em dúvida a afirmativa sobre se tratar de uma sugestão de Marx. Ao revés, não se trata, portanto, de uma prescrição para a cooperação "ideal" ou algo desse tipo, nem uma proposta de Marx ao retorno aos tempos passados, que deu o suporte para a ideia de orgunity do senhor Parker. Trata-se, pois, do confronto entre as formas anteriores da cooperação e a forma capitalista para tornar evidente o caráter particular que a cooperação assume se contrastada com a forma abstrata da cooperação e contrastadas entre si, isto é, a universalidade em relação às formas particulares e entre as próprias particularidades. Em suma, o senhor Parker quer ludibriar seus leitores além de si mesmo de tal maneira que o diletantismo surge como necessário à produção dos mais belos conceitos. 
Este é o melhor lugar para apresentar uma rica passagem presente nos Grundrisse na qual Marx expõe não apenas elementos que evidenciam ainda mais a ingenuidade de se supor que ele apregoava um retorno às formas passadas da cooperação - aliás, acusação infundada e quase geral, encontrada inclusive na boca de homens como ou Peter Drucker (1964) -, porquanto mostra as relações sociais como um produto histórico determinado, mas, sobretudo, como o modo de produção capitalista - e as relações e a forma de cooperação a ele correspondentes - representa a multilateralidade das relações entre os homens e forma a base para desenvolvimentos posteriores. Nessa importante passagem, lemos que:

Se diz e se pode voltar a dizer que a beleza e a grandeza deste sistema residem precisamente neste metabolismo material e espiritual, nesta conexão que se cria naturalmente [de forma inerente], na forma independente do saber e da vontade dos indivíduos, e que pressupõe precisamente sua indiferença e sua independência recíprocas. E seguramente esta independência material é preferível à ausência de relações ou a nexos locais baseados nos vínculos naturais de consanguinidade, ou em relações de senhor e servidão. É igualmente certo que os indivíduos não podem dominar suas próprias relações sociais antes de tê-las criado. Mas é também absurdo conceber esse nexo objetivo como se fosse criado naturalmente, inseparável da natureza da individualidade e imanente a ela (em contraste com seu saber e vontade reflexivos). O nexo é um produto dos indivíduos. É um produto histórico. Pertence a uma determinada fase do desenvolvimento da individualidade. $\mathrm{O}$ estranhamento e a autonomia com que esse nexo existe frente aos indivíduos demonstram somente que estes ainda estão a criar as condições de sua vida social, e que eles ainda não começaram, a partir das ditas condições, a viver tal vida. É o nexo correspondente aos indivíduos inseridos em relações de produção determinadas e específicas. Os indivíduos universalmente desenvolvidos, cujas relações sociais enquanto relações próprias e coletivas estão já submetidas ao seu próprio controle coletivo, não são um produto da natureza, senão da história. $\mathrm{O}$ grau e a universalidade do desenvolvimento das faculdades, nas quais se faz possível esta individualidade, supõem precisamente a produção baseada sobre o valor de troca, que cria, pela primeira vez, ao mesmo tempo que a universalidade do estranhamento do indivíduo frente a si mesmo e aos demais, a universalidade e a multilateralidade de suas relações e de suas habilidades. Em estágios de desenvolvimento anteriores, o indivíduo aparenta maior 
plenitude precisamente porque não está elaborada ainda a plenitude de suas relações e não as pôs frente a ele como potências e relações sociais autônomas. É tão ridículo sentir nostalgias daquela plenitude primitiva como crer que é preciso deter-se neste esvaziamento completo. A visão burguesa jamais se elevou acima da oposição entre ela mesma e sua visão romântica, e por isso a última irá acompanhá-la como uma oposição legítima até sua morte piedosa (MARX, 1987a, p. 89; MARX, 1983a, p. 95; MARX, 1973, p. 161).

Esta passagem única mostra que a sociabilidade que se desenvolve no modo de produção capitalista contrasta com as formas anteriores baseadas no vínculo sanguíneo. O caráter de independência e indiferença mútua que marca esta sociabilidade é, ainda assim, preferível às relações de servidão ou à ausência de qualquer relação. Mas as relações que marcam essa sociabilidade somente podem ser colocadas sob a força da humanidade quando elas próprias forem criadas. Na produção capitalista, tais relações estão autonomizadas e ainda aguardam o momento de serem trazidas de volta sob a vontade consciente e objetiva dos próprios homens livremente associados que por meio delas perpetuam sua existência. O mesmo modo de produção que universaliza o estranhamento e a autonomia dessas relações é o mesmo que radicaliza a multilateralidade dessas mesmas relações, que exacerba a individualidade humana embora não seja o próprio homem a finalidade de sua produção material, mas ele mesmo surge como meio da produção da riqueza; trata-se do reino da valorização das coisas, não de seus produtores. Essa é uma das figuras da contraditoriedade da sociabilidade capitalista e passa a ser nostalgia e romantismo imaginar ou querer de volta "produtos" de outras sociedades passadas quando é a presente que prepara o solo para o desenvolvimento ainda maior da humanidade.

Em decorrência deste ponto, um outro pode ser aqui lançado acerca ainda da forma da atividade produtiva na produção capitalista, qual seja, de que a produção capitalista é fonte do pauperismo. É verdade que Marx analisou o pauperismo como algo latente na produção capitalista, mas não que necessariamente tal produção seja ela mesma a causa simplesmente linear do pauperismo. Marx demarcou muito bem este ponto nas linhas dos Grundrisse ao indicar rapidamente que "O capital, por outra parte, em virtude de que se reproduz continuamente como mais-capital, tem tanto a tendência de pôr como a de abolir esse pauperismo. Opera em direções contrapostas; em um momento prepondera uma, em outro a contraria" (MARX, 1987b, p. 117; MARX, 1983a, p. 511). Quer dizer, a produção de mais-capital gera ora empobrecimento ora alargamento das capacidades de consumo da classe que trabalha, variações no interior do estágio de produção do mais-valor relativo. Talvez, à época de Marx, as tendências 
não fossem para tal alargamento. Isso reverbera no trabalho qualificado e desqualificado, a partir do qual muitos, entre eles Braverman (1974), viram uma suposta degradação unilateral do trabalho no desenvolvimento recente da produção capitalista. Outros ainda cometem o erro oposto ao dizer que, ao contrário do que supostamente disse Marx e Braverman, a produção capitalista gerou qualificação neste último século (e.g. BURAWOY, 1983). Mas isso é parte do movimento do capital, e ambos os lados são parciais. Se produz desqualificação em algumas esferas, produz qualificação em outras esferas; se nas sociedades onde a produção é mais desenvolvida aparece uma intensa qualificação do trabalho, em outras ocorre o oposto, e nas mais desenvolvidas as atividades desqualificadas passam a ser realizadas por trabalhadores oriundos das sociedades em que a produção é menos desenvolvida, por trabalhadores que ou vendem sua força de trabalho para valorização do capital ou trocam seu trabalho por renda, ao prestar serviços pessoais como eletricistas, babás, domésticas, prostitutas etc. Ainda se pode adicionar as complexas relações entre a superexploração do trabalho desqualificado em partes do globo para a qualificação do trabalho em outras regiões. De tal maneira, a produção capitalista produz desqualificação e qualificação e, ainda assim, este ponto nunca foi algo que tomasse a atenção de Marx porque considerava irrelevante a variabilidade da qualificação se no fundamento da produção capitalista está o trabalho abstrato, produtivo, e não necessariamente se ele aparece vestido de terno ou sujo de graxa. O certo é que essa variabilidade, no interior da qual se pode ver avanços e retrocessos, explicita as potencialidades, inclusive regressivas, que a própria sociabilidade do capital comporta. Além do mais, não fora matéria de Marx também porque, certo ou errado, considerava o trabalho socialmente médio como o ângulo para a análise da produção capitalista, a partir do trabalho simples que servia como fundamento para o trabalho complexo, isto é, mede-se o trabalho complexo pelo simples e não o contrário. Esta matéria, estranha, portanto, ao próprio Marx, foi atribuída a ele por análises que acentuavam apenas um lado das tendências.

$\mathrm{Na}$ esteira dessas atribuições, Motta (1981), por exemplo, sugeriu que para Marx a empresa capitalista é uma instância de controle social, que reproduz internamente as "relações de classes mais amplas". Entretanto, a empresa capitalista não pode aparecer apenas como uma instância de controle, pois isso não mostra sua diferença específica e, portanto, não proporciona uma explicação razoável. Da polis grega aos presídios mais modernos, todos possuem alguma forma de controle. O próprio Marx deixou isso mais ou menos esclarecido: ao passo que como a produção capitalista é a produção de mais-valor, o capitalista e as atividades de direção passadas para aquele novo tipo de trabalhador (os gerentes) como função do capital asseguram o funcionamento da produção, a aplicação dos recursos, a presença, os atrasos, incentivos, etc., 
isto é, exercem o controle sobre a produção. Mas, de outra parte, disse Marx em polêmica com Smith, "o capital não é somente, como afirma A. Smith, comando sobre trabalho estranho - no sentido em que o é todo valor de troca, já que dá poder de compra ao seu possuidor -, senão que é o poder de apropriar-se de trabalho estranho sem intercambio, sem equivalente, mas com aparência de intercâmbio" (MARX,1987b, p. 44; MARX,1983a, p. 456). Aqui aparece uma diferença específica da empresa capitalista que, sendo mais do que forma de controle - como o é a igreja, a escola etc. -, é uma forma de apropriação do trabalho vivo no confronto com trabalho morto, isto é, a realização do trabalho produtivo na valorização do capital, seu consumo como mercadoria força de trabalho, uma relação social de produção particular que aparece como mera relação de troca entre equivalentes, cuja aparência geral é a de um simples processo de trabalho. Além do mais, é difícil negar que os tais controles que se desenvolvem na produção capitalista, apesar de que sua finalidade não ser a produção para o homem, mas o homem para a produção, não desempenharam e desempenham algum efeito civilizador no desenvolvimento da sociabilidade presente, da qualidade material requerida para determinados valores de uso sem os quais muitas necessidades reais seriam precariamente atendidas. O problema real é que tais formas, incluindo aí a função de direção, não surgem para outra coisa senão a produção de valores de troca, para a valorização do capital, ao contrário do que pensa, por exemplo, Friedman ao indicar que "As atividades gerenciais são relativamente independentes do tempo" (MARX, 1990, p. 199). Mas, ainda assim, o fato de que tal produção seja o processo de valorização do capital não elimina o caráter contraditório desta forma de exploração do trabalho social. O que dificulta capturar essas diferenças específicas é a tendência sempre marcante em Motta e em outros de se misturar indevidamente Marx e Weber e atribuir ao primeiro coisas que pertencem ao segundo, como, por exemplo, se tratar a empresa capitalista como instância de controle, como a falta de especificação efetiva que marcam os tipos ideais weberianos, uma vez que apenas uma abstração muito arbitrária, apenas abstraindo todas as particularidades da empresa capitalista se pode concebê-la como uma mera instância de controle; uma categoria, pois, que não expressa relações reais e determinadas.

Em paralelo a isso, já foi atribuído por Burawoy (1983) a Marx a descrição de um regime fabril no qual a coerção era o método empregado na produção e que, como contraponto, na atualidade, em que a relação de dependência do trabalho no que se refere ao capital é menor, o método não pode ser a coerção mas a produção ideológica, e que tais métodos variam ainda na atualidade em função daquele grau de dependência; quer dizer, um tipo de contingencialismo sociológico acerca do trabalho que praticamente repete sem saber a propositura de um McGregor (1980) acerca da dependência e da seletividade dos métodos de controle. Em um dos seus principais artigos, Burawoy comete graves abusos de leitura. 
Depois de alguns comentários sobre o que ele chama de "mercado despótico", isto é, aquele regime fabril que supostamente Marx descreveu no qual há uma relação de dependência do trabalho em relação ao capital, diz Burawoy (1983, p. 588):

Como é que a força de trabalho - a capacidade para trabalhar - é convertida em trabalho necessário - aplicação de esforço - para prover salários e lucro? Marx responde, por meio da coerção. Em sua análise, a extração desse esforço ocorre através de um regime despótico de políticas de produção.

Desconsiderando alguns problemas com as formas mais adequadas de algumas categorias indicadas por Burawoy (1983, p. 588), logo na sequência o autor cita ${ }^{2}$ uma passagem presente em $O$ Capital na qual Marx trata da fábrica no capítulo sobre a maquinaria e a grande indústria. Mais especificamente, Marx trata da aplicação maquinal na produção e da disciplina que tal produção requer. "A subordinação técnica do operário ao andamento uniforme do meio de trabalho e a composição peculiar do corpo de trabalho por indivíduos de ambos os sexos e dos mais diversos níveis etários", diz Marx, "gera uma disciplina de caserna, que evolui para um regime fabril completo, e desenvolve inteiramente o trabalho de supervisão, já antes aventado, portanto ao mesmo tempo a divisão dos trabalhadores em trabalhadores manuais e supervisores do trabalho, em soldados rasos da indústria e suboficiais da indústria" (MARX, 1985b, p. 44; MARX, 1962a, p. 447). Essa analogia prosaica aqui aparece para indicar, não que a fábrica funcione como um exército ou que capitalistas tenham se inspirado e aprendido com a forma disciplinar do exército como é frequente ver aludido em livros didáticos. São coisas muito diferentes já que exércitos, quando não consomem o mais-valor produzido também nas fábricas sob a forma de impostos direcionados pelo Estado moderno, costumam produzir apenas carnificina humana, e é preciso uma disciplina militar para fazer ambas as coisas. O que Marx está a indicar é a disciplina e a divisão do trabalho que acompanha a entrada da maquinaria na produção capitalista que se desenvolve mais e mais na forma da fábrica, isto é, a forma pela qual a relação social de produção se realiza na

2 "In the factory code, the capitalist formulates his autocratic power over his workers like a private legislator, and purely as an emanation of his own will, unaccompanied by either that division of responsibility otherwise so much approved of by the bourgeoisie, or the still more approved representative system. This code is merely the capitalist caricature of the social regulation of the labour process which becomes necessary on a large scale and in the employment in common of instruments of labour, and especially of machinery. The overseer's book of penalties replaces the slave-driver's lash. All punishments naturally resolve themselves into fines and deductions from wages, and the law-giving talent of the factory Lycurgus so arranges matters that a violation of his laws is, if possible, more profitable to him than the keeping of them". (MARX, [1867] 1976, p. 549-50) 
produção do capital. Na sequência, vemos a passagem que Burawoy (1983) cita de Marx para que se possa evidenciar a coerção a ele tão cara:

O código fabril, em que o capital formula, por lei privada e domínio próprio, sua autocracia sobre seu trabalhador, sem a divisão dos poderes tão cara fora daí à burguesia e sem o ainda mais amado sistema representativo, é apenas a caricatura capitalista da regulação social do processo de trabalho, que se torna necessária com a cooperação em grande escala e a utilização de meios coletivos de trabalho, notadamente a maquinaria. No lugar do chicote do feitor de escravos surge o manual de penalidades do supervisor. Todas as penalidades se resolvem, naturalmente, em penas pecuniárias e descontos de salário, e a sagacidade legislativa desses Licurgos fabris faz com que a violação de suas leis lhes seja onde possível ainda mais rendosa do que sua observância (MARX, 1985b, p. 44-5; MARX, 1962a, p. 447).

O código fabril é oposto à forma da política que é cara à burguesia. Não é, pois, nem divisão dos poderes nem representação, já que se trata de uma relação econômica; trata-se, como se sabe, de uma relação social de produção desembaraçada das limitações políticas, religiosas, etc. É o domínio do capital sobre o trabalho em que o regime de caserna evolui para um sistema fabril mais completo, com a divisão entre trabalho manual e trabalho de supervisão. Nem é preciso entrar aqui na antiga discussão de Marx (1950) contra Proudhon acerca da introdução da autoridade na fábrica e na sociedade em que, enquanto vigora a anarquia no mercado, na fábrica prevalece a autoridade do capital, dada pela forma de apropriação e pela legislação posterior que a consagra, isto é, o direito como reconhecimento oficial do fato, no diapasão do Mouro. Não obstante, e ainda mais importante, Marx deixa tão claro que é impossível não ver que no lugar do chicote surge o manual de penalidades, isto é, a regulação social do processo de trabalho neste estágio de desenvolvimento da produção capitalista necessário ao trabalho em maior escala, à cooperação e combinação do trabalho sob a forma capitalista, que evoluiu da disciplina de caserna, que abandona a sua forma coercitiva, e encontra na divisão entre trabalho manual e trabalho de supervisão a forma acabada do sistema fabril. Mesmo nas formas posteriores ou nas mais modernas, em que Burawoy (1983) vê menor dependência do trabalho em relação ao capital, ele se esquece que, independente das variadas formas de regulação do processo de trabalho, o despotismo organizado é persistente dado que, como indicou Marx, no modo de produção especificamente capitalista, "não é o trabalho que emprega capital, é o capital que emprega o trabalho" (MARX, 1988, p. 95). Burawoy (1983) parece não entender que "No capital", conforme diz Marx, "a associação 
dos trabalhadores não está imposta por meio de violência física direta, o trabalho forçado, servil ou escravo; está imposta porque as condições de produção são propriedade estranha e existem elas mesmas como associação objetiva, que é o mesmo que acumulação e concentração das condições de produção" (MARX, 1987b, p. 92-3; MARX,1983a, p. 492), quer dizer, condições objetivas que não se alteram dada a variedade das formas de regulação. Burawoy (1983) confunde regulamentação do processo social de trabalho com coerção e faz parecer que Marx descrevia um sistema coercitivo - algo caro ao seu próprio conceito de produção de políticas, isto é, imputação de coisas estranhas às relações sociais de produção e confunde tais relações com seus efeitos na esfera propriamente política em si apartada da esfera da produção econômica -, mas não entendeu que sentido tem a particularização da fábrica enquanto relação social de produção além de não capturar que revolução teve a fábrica no desenvolvimento da sociabilidade perante as formas violentas e coercitivas passadas. Parece que o desenvolvimento de conceitos no interior de algumas sociologias depende de incompreensões generalizadas. Basta ver que as confusões e imprecisões de Burawoy (1983) foram profundamente importantes ao desenvolvimento das discussões na Inglaterra que culminaram nos chamados Estudos críticos da gestão (e.g. WILLMOTT; KNIGHTS, 1990). Mas essa ideia gramsciana aqui requentada é comum também para sugerir, inclusive por autores brasileiros, que para Marx vigorava um conceito de "Estado restrito", que o Estado capitalista nas elaborações do Mouro restringia-se à coerção. É preciso ignorar todo o complexo da elaboração marxiana para sustentar essas ilações absurdas. Recorrendo aos próprios achados de Marx, obtemos um complexo movimento da forma política, variando entre repressão, medidas administrativas, atuação na economia e em problemas sociais, mas sempre em reciprocidades históricas com as forças de ordem primária (cf. PAÇO CUNHA, 2015).

É preciso, pois, determinar um pouco mais tais elementos. Com efeito, a contraditoriedade que se encontra na fábrica mecanizada tem sua base na manufatura que é anterior. Mais uma vez, em O Capital Marx traça as determinações necessárias ao argumento aqui central segundo o qual a relação social de produção especificamente capitalista surge, não apenas como a forma mais desenvolvida da indústria humana, como também contrasta com as formas anteriores pelo grau de civilidade inerente à sua forma de exploração. Em uma excelente passagem para provar tal argumento, diz Marx:

A divisão manufatureira do trabalho cria, por meio da análise da atividade artesanal, da especificação dos instrumentos de trabalho, da formação dos trabalhadores especiais, de seu agrupamento e combinação em um mecanismo global, a graduação qualitativa e a 
proporcionalidade quantitativa de processos sociais de produção, portanto determinada organização do trabalho social, e desenvolve com isso, ao mesmo tempo, nova força produtiva social do trabalho. Como forma especificamente capitalista do processo de produção social - e sob as bases preexistentes ela não podia desenvolver-se de outra forma, a não ser na capitalista - é apenas um método especial de produzir mais-valor relativo ou aumentar a autovalorização do capital - o que se denomina riqueza social, Wealth of Nations etc. - à custa dos trabalhadores. Ela desenvolve a força produtiva social do trabalho não só para o capitalista, em vez de para o trabalhador, mas também por meio da deformação do trabalhador individual. Produz novas condições de dominação do capital sobre o trabalho. Ainda que apareça de um lado como progresso histórico e momento necessário de desenvolvimento do processo de formação econômica da sociedade, por outro ela surge como um meio de exploração civilizada e refinada (MARX, 1985a, p. 286; MARX, 1962a, p. 386).

O grau de aperfeiçoamento técnico e de utilização da força de trabalho combinada que acompanha a manufatura implica numa organização do trabalho social, desenvolvendo a força produtiva do trabalho. Não é outra coisa senão uma relação de autovalorização do capital mediante o consumo produtivo da força de trabalho, produzindo até mesmo anomalias físicas comuns antes dos tempos das legislações fabris e ainda frequentes hoje em certas indústrias. Mas surge como um meio de exploração do trabalho mais civilizado e refinado quando contrastado com os meios coercitivos e violentos do passado. Do ponto de vista apenas material, do desenvolvimento do capital fixo e da técnica, a ciência, como se sabe, desempenhou e desempenha um papel importante na produção capitalista, não apenas desenvolvendo as possibilidades da própria produção de mercadorias, mas também dando uma forma mais específica ao trabalho nessa mesma produção. “Dar à produção um caráter científico é, por fim, a tendência do capital, e se reduz o trabalho a mero elemento desse processo" (MARX, 1987b, p. 221; MARX, 1983a, p. 595). Mas "Por meio desse processo" mesmo de produção, no qual o trabalhador trabalha não para si, mas para a valorização daquilo que se apresenta como um poder estranho a ele, diz Marx (1987b, p. 224; 1983a, p. 597-8): "efetivamente, reduz-se a um mínimo o quantum de trabalho necessário para a produção de um objeto dado, mas somente para que um máximo de trabalho se valorize no máximo de tais objetos. $\mathrm{O}$ primeiro aspecto é importante, porque aqui o capital - de maneira totalmente impremeditada - reduz a um mínimo o trabalho humano, o gasto de 
energias. Isto redundará em benefício do trabalho emancipado e é a condição de sua emancipação".

Para Marx, então, parece que o mesmo processo no qual se aplica a ciência para a melhor produção de mais-valor, cria também as condições para que o trabalho seja reduzido ao mínimo necessário. Ao mesmo tempo em que a produção da riqueza atual se baseia no trabalho produtivo e tem o tempo como a medida desse trabalho, ela reduz esse mesmo trabalho a um mínimo necessário, "convertendo-o sempre em trabalho excedente" (MARX, 1987b, p. 229; MARX, 1983a, p. 602). Esse é um produto da própria relação social de produção na qual o trabalhador "se apresenta ao lado do processo de produção, em lugar de ser seu agente principal". Na sequência dessa última passagem, diz Marx (1987b, p. 228; 1983a, p. 601):

\begin{abstract}
Nesta transformação o que aparece como o pilar fundamental da produção e da riqueza não é nem o trabalho imediato executado pelo o homem nem o tempo que este trabalha, senão a apropriação de sua própria força produtiva geral, sua compreensão da natureza e seu domínio da mesma graças a sua existência como corpo social; em uma palavra, o desenvolvimento do indivíduo social [gesellschaftlichen Individuums]. O roubo de tempo de trabalho estranho, sobre o qual se funda a riqueza atual, aparece como uma base miserável comparada com este fundamento, recém desenvolvido, criado pela grande indústria mesma.
\end{abstract}

A produção de valores de troca é a condição da criação moderna desse indivíduo social, desse corpo social cuja força produtiva é incorporada ao capital. Mas essa incorporação aparece como uma coisa menor se comparada à criação dessa grande indústria, isto é, este mesmo corpo social de produção coletiva. Não é, porém, um tipo de aprovação de Marx ou algo do gênero. Trata-se de uma constatação à maneira marxiana segundo a qual:

O capital mesmo é a contradição em processo /.../. Por um lado, desperta para a vida todos os poderes da ciência e da natureza, assim como da cooperação e do intercâmbio social, para fazer com que a criação da riqueza seja (relativamente) independentemente do tempo de trabalho empregado nela. Por outro lado, se propõe a medir com o tempo de trabalho essas gigantescas forças sociais criadas desta maneira e reduzi-las aos limites requeridos para que o valor já criado se conserve como valor. As forças produtivas e as relações sociais - ambos aspectos diversos do desenvolvimento do indivíduo social - aparecem ao capital unicamente como meios, e não são para ele mais do que meios para produzir fundamentado 
em sua mesquinha base (MARX, 1987b, p. 229; MARX, 1983a, p. 601-2).

Aqui se apresenta a contraditoriedade com muita força, porquanto tal caráter é imanente ao capital mesmo. Traz à vida a ciência, a cooperação, etc., ao mesmo tempo que o faz para converte-los em meros meios de sua própria reprodução. E é exatamente por aparecer na qualidade de meio para a produção de valores de troca que a força coletiva surge como um corpo social e, ao mesmo tempo, as condições postas por essa mesma produção tornam-se condição para a sua própria abolição porque, diz Marx nessa direção,

[...] tende a um desenvolvimento universal das forças produtivas e se converte na premissa de um novo modo de produção, que não está fundado sobre o desenvolvimento das forças produtivas com vistas a reproduzir e ampliar uma situação determinada, senão que é um modo de produção no qual o mesmo desenvolvimento livre, expedito, progressivo e universal das forças produtivas constitui a premissa da sociedade e por fim de sua reprodução; na qual a única premissa é superar o ponto de partida (MARX, 1987b, p. 31; MARX, 1983a, p. 445).

A contraditoriedade do modo de produção capitalista e, portanto, das próprias relações sociais de produção resultantes e condicionantes dessa mesma produção expressa os próprios limites inerentes a essa forma particular da produção. "O limite do capital", diz Marx logo na sequência, "consiste em que todo este desenvolvimento se efetua antiteticamente e no qual a elaboração das forças produtivas, da riqueza geral, etc., do saber, etc., apresenta-se de tal maneira que o próprio indivíduo laborioso se estranha; relaciona-se com as condições reais de sua própria abolição" (MARX, 1987b, p. 33; MARX, 1983a, p. 447). Tudo indica que Marx, certo ou errado, tinha em mente que o centro de trabalho "embora em sua forma capitalista espontaneamente brutal, em que o trabalhador comparece para o processo de produção e não o processo de produção para o trabalhador -, fonte pestilenta de degeneração e escravidão, tenha, sob circunstâncias adequadas, de converter-se inversamente em fonte de desenvolvimento humano" (MARX, 1985b, p. 91; MARX, 1962a, p. 514). Isso mostra a contraditoriedade da forma particularmente capitalista da relação social de produção que, embora composta por um processo de produção que é processo de valorização do capital e, portanto, do comando do capital sobre o trabalho, prepara as condições para o desenvolvimento verdadeiramente humano, algo que até agora tem atingido apenas as condições de trabalho, apenas as melhorias marginais que são igualmente ou imposições legais ou pontos sobre os quais a 
produção pode gerar ainda mais valor, mas não o máximo desenvolvimento do gênero humano e dos indivíduos. É possível sustentar toda essa argumentação aqui apresentada por algumas últimas considerações de Marx, as quais reforçam aquela contraditoriedade, devidamente esquecida por tantos estudiosos. "Um dos aspectos civilizadores do capital", diz ele:

[...] é que ele extrai esse mais-trabalho de uma maneira e sob tais condições que são mais vantajosas para o desenvolvimento das forças produtivas, das relações sociais e para a criação dos elementos para uma nova formação mais elevada do que sob as formas anteriores da escravidão, da servidão etc. Por um lado, leva assim a um nível em que desaparece a coerção e a monopolização do desenvolvimento social (inclusive de suas vantagens materiais e intelectuais) por meio de uma parte da sociedade à custa da outra; por outro lado, produz os meios materiais e o germe para relações que, numa forma mais elevada da sociedade, permitem unir esse maistrabalho a uma limitação maior do tempo em geral dedicado ao trabalho material (MARX, 1985c, p. 273; MARX, 1962b, p. 827)

É no próprio modo de produção capitalista que a coerção imediata na produção desaparece - sem ser a eliminação da compulsão econômica e ele mesmo prepara os desenvolvimentos posteriores, na medida em que novas relações se desenvolvam. Não por menos, Marx já havia indicado em 1857 que "A sociedade burguesa é historicamente a mais desenvolvida e a mais diferenciada organização da produção" (MARX, 1983b, p. 39). Não resta dúvida de que a contraditoriedade que Marx constatou fora apagada da cabeça de muitos estudiosos e ficam claros os horrores teóricos que são feitos quando por desconhecimento ou por diletantismo subvertem-se os lineamentos de Marx precisamente ancorados no movimento material para a construção dos maravilhosos conceitos dessa ou daquela sociologia, em lados diferentes do Atlântico, acima e abaixo da linha do equador.

A questão da contraditoriedade não permite apenas apreender a multilateralidade posta com o desenvolvimento da produção capitalista, nem apenas o real significado da relação social de produção, do centro de trabalho, na história da humanidade. Não permite tão somente a constatação de que a própria relação social de produção contém em si mesma as condições de sua superação, pois, ao se apresentar como forma mais refinada e civilizada de exploração na geração de mais-valor que reduz ao mínimo necessário o mesmo trabalho do qual depende, prepara o terreno para o aparecimento das necessidades mais universais, elimina a fragmentação do trabalho e transcende as limitações individuais, embora 
produza, igualmente, a maior competição no interior do próprio trabalho, maior aprofundamento da exploração do próprio trabalho com o incremento técnico-científico.

Tal contraditoriedade permite igualmente a apreensão dos limites de algumas leituras muito ligeiras sobre os problemas apontados. Se, por um lado, viu-se que não há qualquer clamor por parte de Marx de um retorno às formas passadas do trabalho e da cooperação, nem que a avaliação do trabalho produtivo tenha por ângulo o trabalho artesanal, por outro lado, viu-se que o próprio Marx considerava superadas as formas coercitivas diluídas com a entrada da regulação do processo de produção por parte dos Licurgos fabris, isto é, a própria produção capitalista trouxe consigo relações sociais de exploração do trabalho mais refinadas.

Em outros termos, Marx não descreveu um regime fabril e especialmente Burawoy (1983) confundiu despotismo organizado com coerção virulenta, confusão necessária aos fabulosos conceitos como se pôde ver também em Parker e como o seu próprio maravilhoso conceito se ergue pela supressão descabida das passagens que, se apresentadas como aqui o foram - destronam tais conceitos de suas fictícias soberanias.

Por outro lado, ainda, viu-se que a produção capitalista produz pauperismo, mas também sua diminuição, produz desqualificação, mas também qualificação, de acordo com o momento do seu desenvolvimento e com os pontos de sua produção numa articulação global. De tal maneira, a degradação do trabalho no século XX ou o seu oposto, unilateralmente, são parcialidades de entendimentos que capturam apenas uma das tendências.

Ao revés dessas leituras, os lineamentos do próprio Marx mostram que a produção capitalista, assim como as relações sociais de produção sobre as quais ela se assenta, é simultaneamente a forma antagônica e mais desenvolvida que a humanidade pôde estabelecer na relação consigo mesma e com a natureza, mas não a última.

\section{Referências}

BRAVERMAN, H. Trabalho e capital monopolista: a degradação do trabalho no século XX. Rio de Janeiro: Zahar, 1974.

BURAWOY, M. Between the labor process and the state: the changing face of factory regimes under advanced capitalism. American Sociological Review, October, vol. 48, 1983, pp. 587-605.

DRUCKER, P. The concept of the corporation. Winnipeg: Mentor, 1964. 
FRIEDMAN, A. Managerial strategies, activities, techniques and technology: towards a complex theory of the labour process. In: Willmott, H; Knights, D. Labour process theory. Macmillan press, London, 1990.

GIANNOTTI, J. A. Origens da dialética do trabalho. Porto Alegre: LPM editores, 1985.

MARX, K. Misère de la philosophie. Paris: Alfred Costes Éditeur, 1950.

1962a.

. Das Kapital. Werke, Dietz Verlag, Berlin. Band 23, Erster Band,

_. Das Kapital. Werke, Dietz Verlag, Berlin. Band 23, Dritter Band, 1962b.

Grundrisse: Introduction to the critique of political economy. New York: Vintage Books, 1973.

. Grundrisse der kritik der politischen Ökonomie. Werke, Dietz Verlag Berlin, Band 42, 1983a.

. Einleitung zu den Grundrissen der kritik der politishchen Ökonomie. Werke, Band 42, Dietz Verlag Berlin, 1983b.

. O Capital. vol 1. São Paulo: Nova Cultural, 1985a.

. O Capital. vol 2. São Paulo: Nova Cultural, 1985b.

. O Capital. vol 5. São Paulo: Nova Cultural, 1985c.

- Elementos fundamentales para la crítica de la economia política (Grundrisse) 1857-1859. Vol 1. Mexico: Siglo Veintiuno, 1987a.

- Elementos fundamentales para la crítica de la economia política (Grundrisse) 1857-1859. Vol 2. Mexico: Siglo Veintiuno, 1987b.

Economic Manuscript. Collected Works. Vol 30. London: Lawrence \& Wishart, 1988.

MCGREGOR, D. O lado humano da empresa. São Paulo: Martins Fontes, 1980.

MÉSZÁROS, I. Para além do capital. São Paulo: Boitempo, 2002.

MOTTA, F. P. O que é burocracia. São Paulo: Brasiliense, 1981.

PAÇO CUNHA, E. Movimento real da forma política em Marx: elementos para a crítica dos "aparelhos repressivos" como síntese do estado capitalista. 
MARX E A CONTRADITORIEDADE DA RELAÇÃO SOCIAL DE PRODUÇÃO ESPECIFICAMENTE

CAPITALISTA

Elcemir Paço Cunha

Marx e o Marxismo 2015: insurreições, passado e presente. Niterói, UFF, 2015.

PARKER, M. Against Management. Cambridge: Polity, 2002.

WILLMOTT, H; KNIGHTS, D. Labour process theory. Macmillan press, London, 1990.

Submetido em: 08/07/2016

Aprovado em: 01/09/2016 